\title{
THERMO-PORO-MECHANICAL PROPERTIES OF THE AIGION FAULT CLAYEY GOUGE-APPLICATION TO THE ANALYSIS OF SHEAR HEATING AND FLUID PRESSURIZATION
}

\author{
Jean Sulem ${ }^{\mathrm{i})}$, Ioannis Vardoulakisii), Hichem Ouffroukhiii) and Vassilis Perdikatsisiv)
}

\begin{abstract}
In this paper, the mechanism of fault pressurization in rapid slip events is analyzed on the basis of a complete characterization of the thermo-poro-mechanical behavior of a clayey gouge extracted at $760 \mathrm{~m}$ depth in Aigion fault in the active seismic zone of the Gulf of Corinth, Greece. It is shown that the thermally collapsible character of this clayey gouge can be responsible for a dramatic reduction of effective stress and a full fluidization of the material. Moreover a back analysis of an existing slip surface inside the clayey core of the fault shows that this failure plane is compatible with principal stress directions locally parallel and perpendicular to the fault axis.
\end{abstract}

Key words: clay, fault, shear-band analysis, shear deformation, thermo-poro-mechanical couplings (IGC: B4/D6)

\section{INTRODUCTION}

The interest of the interactions between circulating fluids and fault mechanics with particular focus on the hydro-thermo-mechanical couplings has been renewed in the geophysics community during the recent years. Active fault drilling operations of the Geological Survey of Japan at Nojima Hirabayashi (Otsuki et al., 2003) and of the Corinth Rift Laboratory at Aigion have put emphasis on core sample collections in the fault zones in order to study material properties (strength, permeability, porosity) of fault gouge and the effect of pore pressure and temperature in earthquake rupture processes.

Shear heating tends to increase pore pressure and to decrease the effective compressive stress and the shearing resistance of the fault material (Lachenbruch, 1980; Mase and Smith, 1985). On the other hand dilatancy tends to decrease pore pressure. Such couplings have been studied thoroughly in a recent paper of Garagash and Rudnicki (2003). Fault zones are often characterized by large amounts of clay minerals, which form well-defined structures and orientation within the fault zone. These clay minerals inside the fault gouge are widely believed to significantly affect the mechanical behavior of faults since as is the case for normally consolidated clays, they tend to contract when heated.

Based on the above mentioned literature and the recent experimental work by Sultan et al. (2000), Vardoulakis (2002a, b) has demonstrated the importance of thermally collapsible and thermally softening clay on the overall dynamic thermo-poro-mechanical behavior of clay-rich gouges. The sensitive parameter for the description of the thermo-poro-mechanical coupling is the thermal expansion coefficient of the material. Possible collapse of the clay under thermal loading may activate fluid pressurization inside the fault and lead to substantial reduction of the apparent friction.

Within the frame of the 'CRL' (Corinth Rift Laboratory project) (Cornet et al., 2004a) centered on the south western sector of the Gulf of Corinth (http://www. corinth-rift-lab.org), fault zone cores from the active Aigion fault have been collected continuously from depths between $708 \mathrm{~m}$ to $782 \mathrm{~m}$. As part of the project, our work was focused on the thermo-poro-mechanical characterization of fault gouge from the Aigion well.

In a previous recent paper, preliminary results from mechanical laboratory analyses on specimens taken from the Aigion fault core have been presented (Sulem et al., 2004). Special attention has been paid to temperature effects on the behavior of the clayey core of the lower part of Aigion fault drilling core. In this paper, the mechanical characterization of fault zone materials is completed by presenting results of laboratory experiments performed on samples cored in various zones of the clayey core. Emphasis is given on the comparison of the hydraulic behavior of the two different parts of the clayey

i) Director of Research, CERMES, Ecole Nationale des Ponts et Chaussées, 6-8 Av. Blaise Pascal, Cité Descartes, Champs sur Marne, 77455 Marne-La-Vallée Cedex 2, France (sulem@cermes.enpc.fr).

ii) Professor, Faculty of Applied Mathematics and Physics, National Technical University of Athens, 157 73, Greece.

iii) Doctoral Student, CERMES, Ecole Nationale des Ponts et Chaussées/LCPC, Institut Navier, Marne-La-Vallée, 77455, France.

iv) Associate Professor, Department of Mineral Resources, Technical University of Crete, Chania 73100, Greece. The manuscript for this paper was received for review on May 12, 2004; approved on September 24, 2004. Written discussions on this paper should be submitted before November 1, 2005 to the Japanese Geotechnical Society, 4-38-2, Sengoku, Bunkyo-ku, Tokyo 112-0011, Japan. Upon request the closing date may be extended one month. 


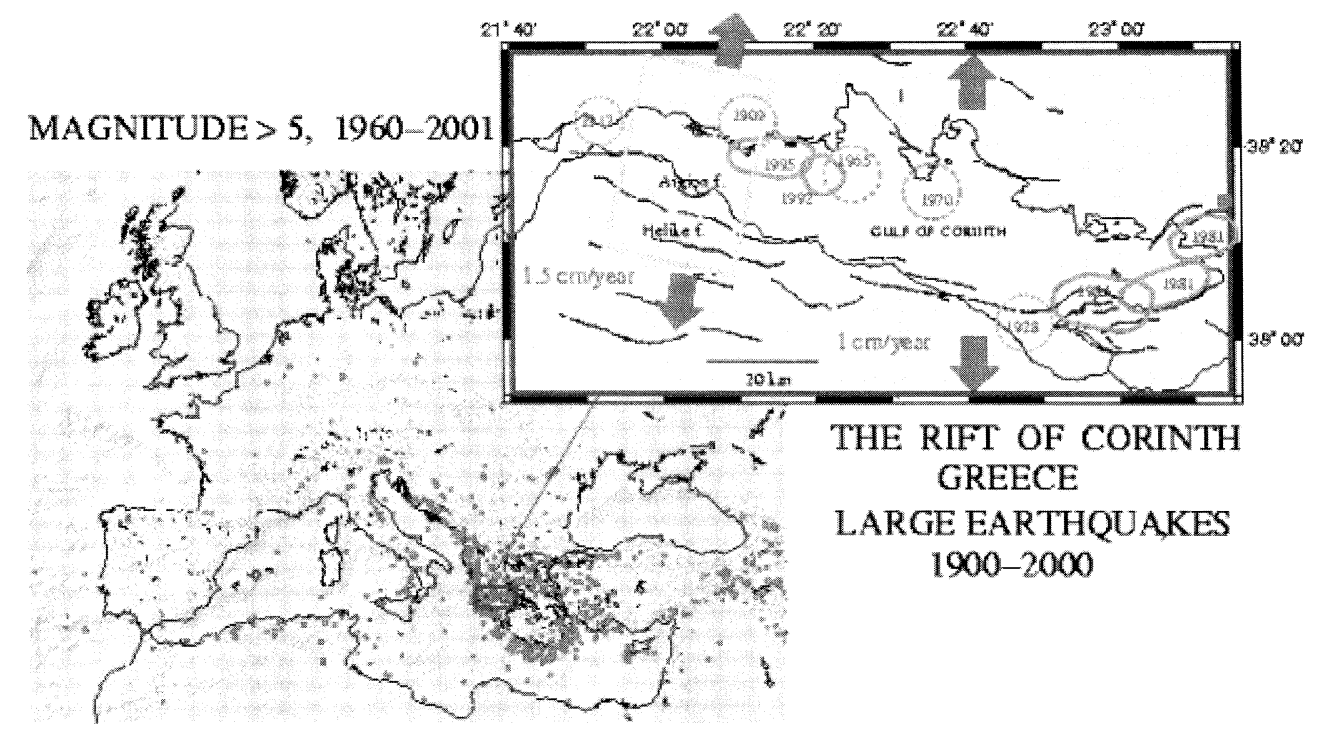

Fig. 1. General sismo-tectonic context of the Corinth Rift. The CRL location is the green rectangle centered on Aigion. Recent earthquakes are indicated by their date and the approximate size of their seismic rupture. The European map shows all seismic events with magnitude larger than 5, as observed from 1960 to 2001 (from Cornet et al., 2004a)

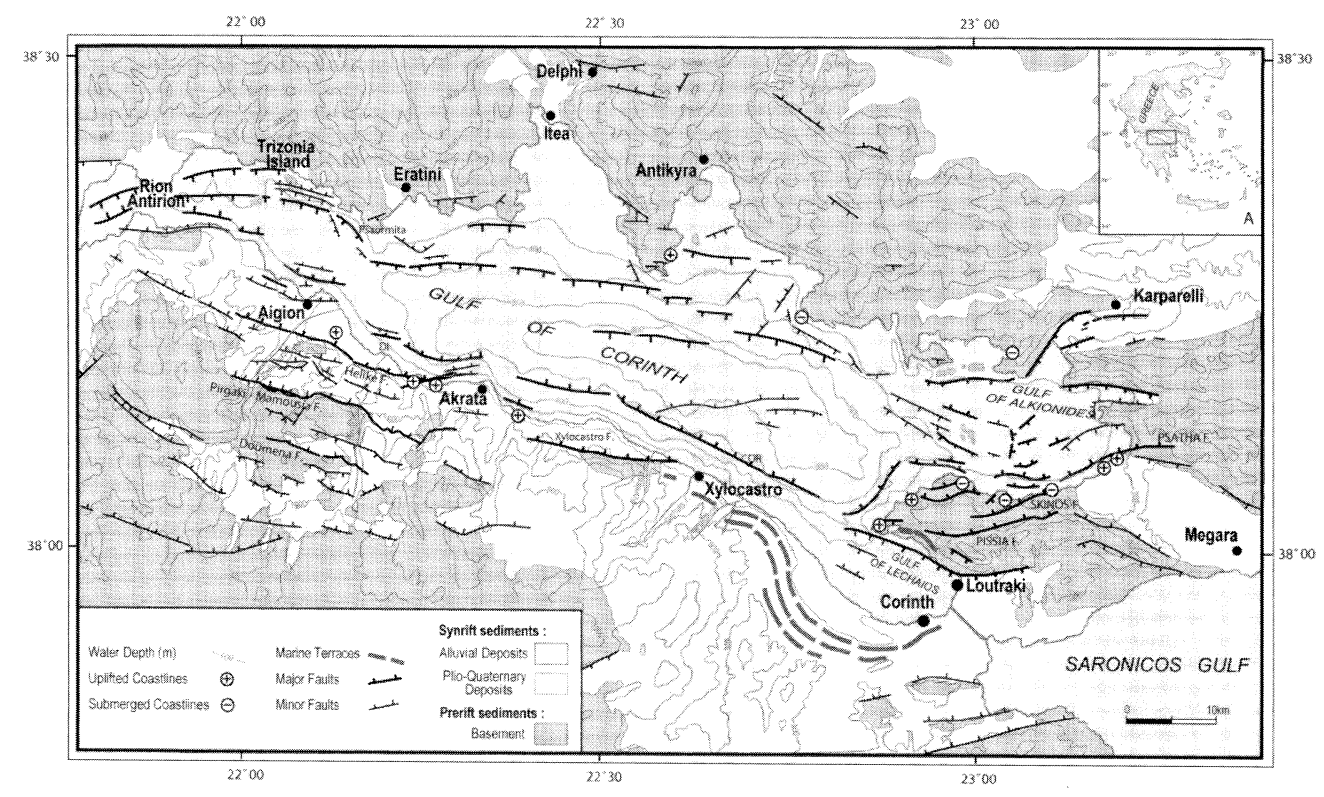

Fig. 2. Geological map of the Gulf of Corinth (from Moretti et al., 2003)

core: one which consists mostly of siliceous material and the other which consists mostly of calcareous material and which is in direct contact with the limestone brecciated zone above. A permeability model and a constitutive model are proposed for clayey gouge material. Inside the clayey core, a clear shearing surface with marked slip lines is visible on a plane that makes a $68^{\circ}$ angle with respect to the core axis. This failure surface was not induced by the decompression process but is indeed a slip plane as clear striation is observed at the interface (see Fig. 14). A strain localization analysis is performed to extract from the observation of this shear plane, information on the state stress in the fault zone. Finally, an analysis of rapid shearing phenomenon is proposed and effects on pore pressure and temperature evolution are analyzed.

\section{GEOLOGICAL STRUCTURE}

The Gulf of Corinth is the most seismically active zone in Europe and the fastest opening area of continental break-up, with up to $1.5 \mathrm{~cm} /$ year of north-south extension and more than $1 \mathrm{~mm} /$ year of uplift of the southern shore (Tselentis and Makropoulos, 1986) (Fig. 1 from Cornet et al., 2004a). A geological map of the area recently published by Moretti et al. (2003) is shown on Fig. 2.

A detailed analysis of the geological structure of the 


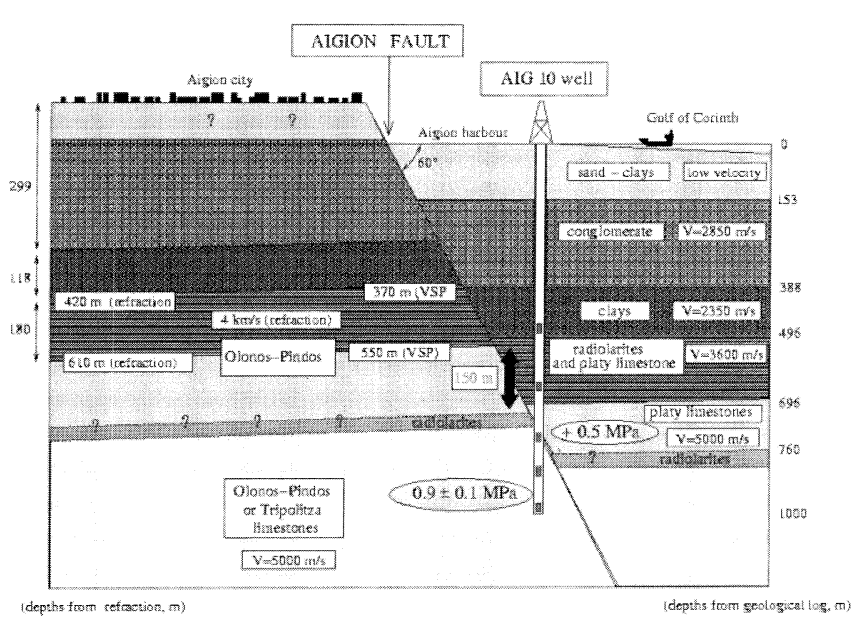

Fig. 3. Schematic structural cross section through Aigion fault, in Aigion harbour (from Cornet et al., 2004b)

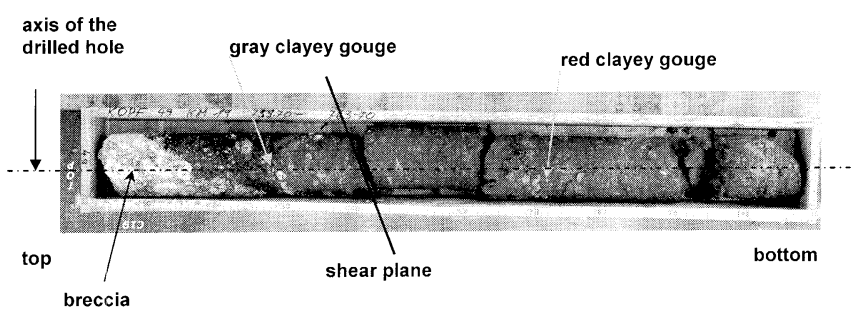

Fig. 4. Box 49 containing the core at depth $759.70 \mathrm{~m}$, characterized as "Aigion fault" core

studied area is presented in the recent paper of Micarelli et al. (2003). During drilling in the active Aigion fault, cuttings were collected, geophysical logs, including borehole imaging and sonic logs as well as vertical seismic profiles, were completed. This has provided material for a detailed lithological and structural investigation of the formations intersected by the well presented in the paper of Rettenmaier et al. (2004). Results are summarized in Fig. 3 (from Cornet et al., 2004b).

At depth $760 \mathrm{~m}$ the Aigion fault was intercepted, deeping at an angle of about $60^{\circ}$. The heart of the fault is a zone of clay-rich material derived from radiolarites on a length of about $1 \mathrm{~m}$ (Fig. 4). As mentioned above a clear shear plane separates the clayey core into two distinct parts recognizable by the gray color of the upper part called in the following 'gray clayey gouge' and the red brown color of the lower one called in the following 'red clayey gouge'. Above and below, brecciated limestones constitute the heavily damaged zone (Fig. 5). The thickness of this zone is $3 \mathrm{~m}$ above the Aigion fault and $9 \mathrm{~m}$ below (Daniel et al., 2004).

\section{LABORATORY CHARACTERISATION OF CLAYEY GOUGE}

\section{Samples Preparation and In-situ Stress}

In geotechnical engineering special techniques exist to obtain high-quality undisturbed soil samples and try to

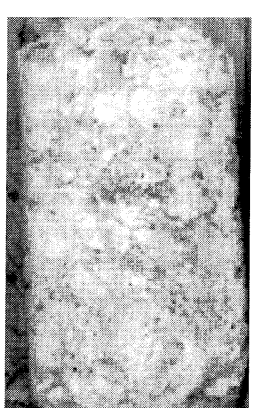

(a)

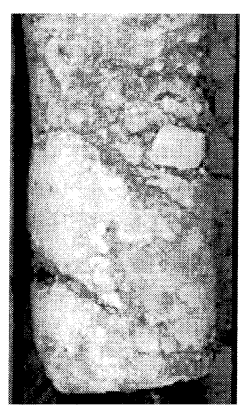

(b)
Fig. 5. Brecciated limestone above (a) and below (b) the "Aigion fault" core

prevent alteration of soil structure. It is however very difficult to obtain undisturbed samples from great depths. Unfortunately within the frame of DG-Lab project no resources could be made available to use these techniques and the cores have been disturbed to some degree during sampling and transportation. However this is not so detrimental for the type of gouge material that was recovered as it can be with cemented sands or with soft clays.

As reports from the drilling site confirm, the clayey gouge which was extracted from Aigion fault was a remarkably soft material (see Fig. 4). Most probably this is because this material was continuously stressed due to the aseismic and seismic movements of the fault. Thus it is expected that the effect of remoulding is of lesser importance, as long as the density and the water content of the samples are preserved for testing.

The in-situ density of the material is reasonably retrieved by applying the in-situ stresses onto the sample. As results from direct stress measurements inside the borehole are not available at present, the in-situ state of stress has to be estimated. Assuming that the density of the overburden is about $2.5 \mathrm{gr} / \mathrm{cm}^{3}$ we estimate a total vertical stress of about $19 \mathrm{MPa}$, which in turn is corresponding to an effective vertical stress of 11.4 MPa.

Once the Aegion fault core was taken from the borehole, it was stored for few days on site and then it was transported to the Soil Mechanics Laboratory of Ecole Nationale de Ponts et Chaussées, where it was stored in a room with controlled temperature and humidity. Obviously it was not possible to avoid partial drying of the core during extraction, storage and transportation but then it was regularly wetted as soon as it was stored in good conditions. As it was not possible to use in the experiments the same saturation fluid as in-situ, we have used demineralised water in which a certain amount of particles from the sample have been placed during 24 hours. The mixture has been then filtered and the resulting fluid has been used for the saturation of the tested samples. This technique is commonly used in soil testing to avoid any chemical influence of the saturation fluid on the mechanical properties of the tested material. 
Particle Size Characteristics, Atterberg Limits and Mineralogy of the Material

Figure 6 shows the grain-size distribution curves for the red and the gray Aigion fault clay materials. It can be seen that the samples are non-homogeneous. Sieve technique has been used for the fraction with particle size greater than 80 microns and hydrometer technique has been used for the fraction with particle size smaller than 80 microns. The coarse fraction for the red material corresponds to radiolarite fragments. For the red clayey gouge, the percentage of fines (fraction smaller than $80 \mu \mathrm{m}$ sieve size) is $32 \%$ and the percentage of clay particles (mass fraction smaller than $2 \mu \mathrm{m}$ ) is about $15 \%$. For the gray clayey gouge, the percentage of fines is $49 \%$ and the percentage of clay particles is about $25 \%$.

The grain-size distribution curves are approximated

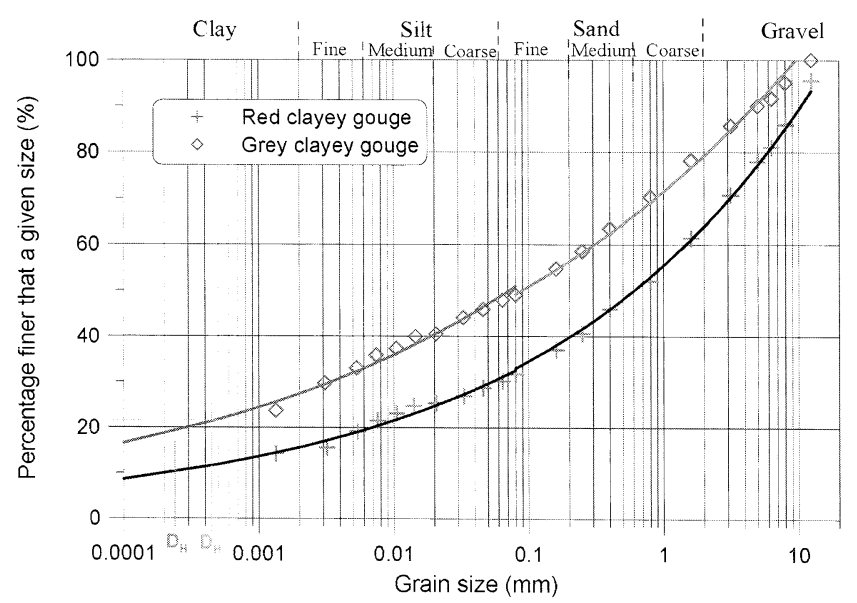

Fig. 6. Grain size distribution

Table 1. Parameters of the power law of the grain-size distribution curves

\begin{tabular}{c|c|c|c|c}
\hline \multirow{2}{*}{} & \multicolumn{2}{|c|}{ Red clayey gouge } & \multicolumn{2}{c}{ Gray clayey gouge } \\
\cline { 2 - 5 } & $D<0.08 \mathrm{~mm}$ & $D \geq 0.08 \mathrm{~mm}$ & $D<0.08 \mathrm{~mm}$ & $D \geq 0.08 \mathrm{~mm}$ \\
\hline$D_{\text {ref }}(\mathrm{mm})$ & 23 & 17.5 & 4.45 & 9.54 \\
\hline$r$ & 0.198 & 0.206 & 0.168 & 0.148 \\
\hline
\end{tabular}

with a power law:

$$
N=\left(\frac{D}{D_{\text {ref }}}\right)^{\mathrm{r}}
$$

where $N$ is the fraction in weight of particles with a diameter smaller than a particle size $D$ and the parameters $D_{\text {ref }}$ and $r$ are given in Table 1 .

The Atterberg limits of the two materials are:

For the red clayey gouge

Liquid Limit LL $=29 \%$, Plastic Limit PL $=15 \%$ which corresponds to a relatively low Plasticity Index $(\mathrm{PI}=$ $14 \%)$. According to the USC system, the material is classified as a "clayey sand".

For the gray clayey gouge

Liquid Limit LL $=46 \%$, Plastic Limit PL $=30 \%$ which corresponds to a relatively low Plasticity Index $(\mathrm{PI}=$ $16 \%$ ). According to the USC system, the material is classified as a "clayey silt".

The mineralogical analysis of the samples was carried out by X-ray diffraction. A Siemens D500 Powder Diffractometer was used, with copper tube and graphite monochromator. The quantitative analysis was carried out by Rietveld refinement techniques. The amorphous content was determined by the addition of an internal standard (Silicon) and the above technique.

The fragments as well as the clay matrix have been studied. The results are shown on Tables 2(a) and (b).

On these tables the mineral composition is normalized to $100 \%$. The amorphous content is about $20 \%$ for the red material and $40 \%$ for the gray one. Taking into account the amorphous content, the real crystalline phases content is obtained by multiplying the mineral content of Table 2(a) by a factor 0.8 and the one of Table 2(b) by a factor 0.6. We notice that the red gouge contains illite and hematite (responsible for the red coloration) but no calcite and no chlorite which are present in the gray material.

On Fig. 7, pictures of the red clayey gouge and of the gray clayey gouge as observed with the electron scanning microscope are presented. According to the electron scanning microscopy the red clayey gouge is finer that the gray one.

Table 2(a). Mineral composition of red fault clayey gouge

\begin{tabular}{c|c|c|c|c}
\hline Sample & Quartz $(\%)$ & Chlorite (\%) & Illite (\%) & Albite (\%) \\
\hline Clay particles $<80 \mu \mathrm{m}$ & 74 & 3 & 10 & 9 \\
\hline Clay matrix $<400 \mu \mathrm{m}$ & 66 & 2 & 15 & 13 \\
\hline Fragments and gravels & 73 & 2 & 9 & 8 \\
\hline
\end{tabular}

Table 2(b). Mineral composition of gray fault clayey gouge

\begin{tabular}{c|c|c|c|c}
\hline Sample & Quartz (\%) & Chlorite (\%) & Calcite (\%) \\
\hline Clay particles $<80 \mu \mathrm{m}$ & 49 & 47.4 & 2.5 \\
\hline Clay matrix $<400 \mu \mathrm{m}$ & 56 & 34 & 6.5 \\
\hline Fragments and gravels & 61 & 24 & 2.5 \\
\hline
\end{tabular}




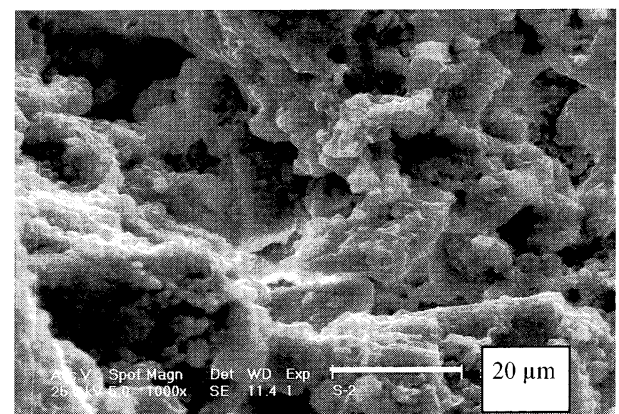

(a)

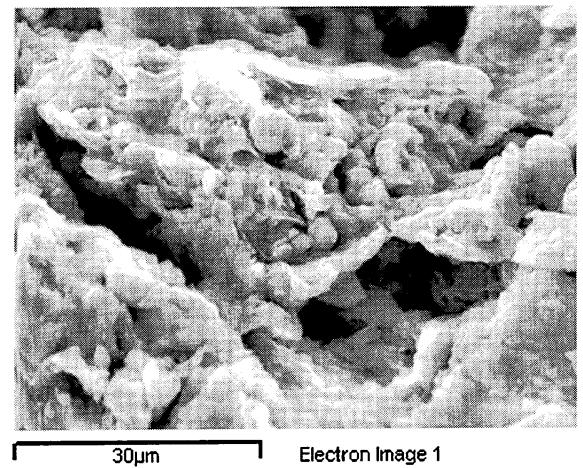

(b)

Fig. 7. Red clayey gouge: (a) and gray clayey gouge and (b) observed with the electron scanning microscope

\section{Specific Surface}

For the red clayey gouge the specific surface is evaluated by using the methylene blue adsorption technique. $10 \mathrm{~g}$ of dry soil suspension from the fraction with a grain size smaller than 80 microns have been used with a $10 \mathrm{~g} / \mathrm{l}$ methylene blue solution. The end point detection is performed by spot testing on filter paper. The mass of introduced methylene blue to reach the end point (i.e. the methylene blue has replaced cations in the double layer and coated all the mineral surfaces) is $0.385 \mathrm{~g}$ corresponding to the so-called 'Blue index' VBS $=3.85$. The specific surface of the soil is deduced from the relation

$$
S_{\mathrm{s}}=\frac{1}{W_{\mathrm{MB}}} \frac{m_{\mathrm{B}}}{m_{\mathrm{S}}} * A_{\mathrm{MB}} * A_{\mathrm{V}}
$$

where $m_{\mathrm{B}}$ and $m_{\mathrm{S}}$ are respectively the mass of methylene blue and of dry soil, $W_{\mathrm{MB}}$ is the Molecular weight of Methylene blue $=319.87 \mathrm{~g} / \mathrm{mol}, A_{\mathrm{MB}}$ is the area covered by one methylene blue molecule which is about $=130 \AA^{2}$, $A_{\mathrm{v}}$ is the Avogadro number $=6.02 \times 10^{23}$. The specific surface obtained is $S_{\mathrm{s}}=94.3 \mathrm{~m}^{2} / \mathrm{g}$ which is typical of an illite.

The same technique is applied for the gray clayey gouge for which we obtain a slightly larger specific surface: $S_{\mathrm{s}}=112 \mathrm{~m}^{2} / \mathrm{g}$.

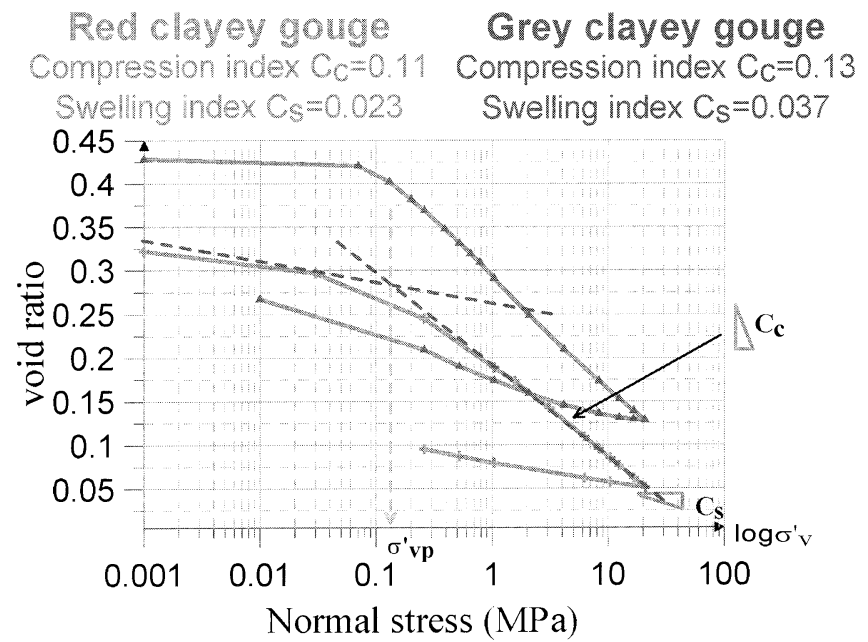

Fig. 8. Oedometric compression curves

\section{THERMO-PORO-MECHANICAL CHARACTERISATION OF CLAYEY GOUGE}

Oedometric Compression Test

The oedometric compression test is commonly used in Soil Mechanics practice to characterize the compressibility of a soil. For geophysics application, it appears also as a useful test as the compression and the swelling indices are the two relevant parameters to describe the response of the material under compression for the range of stresses around its 'natural' in situ-stress (here this range is from 10 to $20 \mathrm{MPa}$ ).

Oedometric compression tests performed on saturated samples of both materials have been performed using the high-pressure oedometer system of CERMES. A system of double cantilever beam allows a maximum vertical load of $12 \mathrm{t}$ corresponding to a maximum stress of about $31 \mathrm{MPa}$ on a cylindrical sample with a diameter of $70 \mathrm{~mm}$ (Marcial et al., 2002). Results are presented on Fig. 8.

The small value of the pre-consolidation stress shows that the material has been remolded during the coring process and has lost the memory of the loading history. The measured compression indices $\left(C_{\mathrm{c}}=0.11\right.$ for the red clayey gouge and $C_{\mathrm{c}}=0.13$ for the gray one) are typical of a sandy clay.

The oedometric test allows the determination of the isothermal compressibility coefficient

$$
c=\frac{1}{1+e} \frac{\bar{C}_{\mathrm{c}}}{\left|\sigma^{\prime}\right|}, \quad \bar{C}_{\mathrm{c}}=\frac{C_{\mathrm{c}}}{\ln (10)}
$$

where $\sigma^{\prime}$ is the effective normal stress. Thus for loading at 11.4 $\mathrm{MPa}$, the isothermal, compressibility coefficient is estimated as $c \approx 0.0039 \mathrm{MPa}^{-1}$ for the red clay and as $c \approx 0.0013 \mathrm{MPa}^{-1}$ for the gray clay.

\section{Permeability Model}

By applying the principles of the consolidation theory commonly used in geotechnical engineering, it is possible at each stage of loading to evaluate the one-dimensional consolidation coefficient $c_{\mathrm{v}}$ using Taylor or Casagrande 


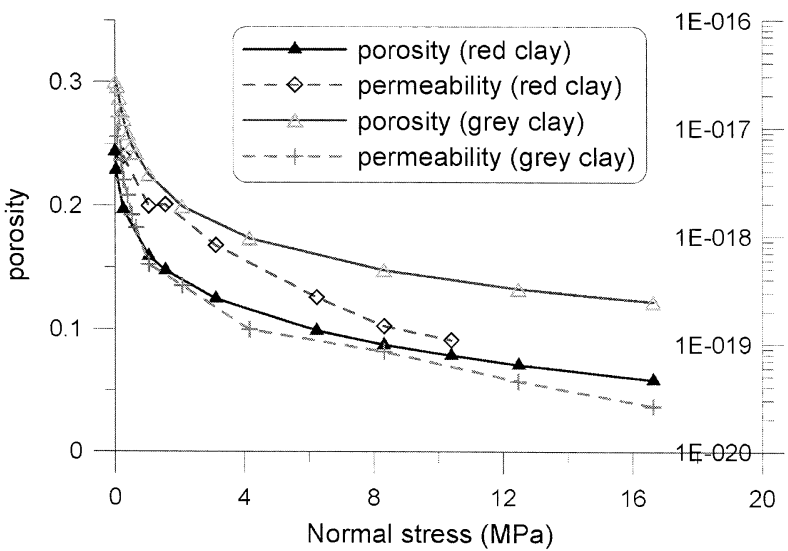

Fig. 9. Evolution of the porosity (in full line) and of the permeability (in dotted line) during oedometric compression of gouge material

methods. The hydraulic conductivity of the gouge is evaluated as a function of the applied oedometric pressure (Fig. 9)

$$
k_{\mathrm{w}}=c_{\mathrm{v}} \frac{\rho_{\mathrm{w}} g}{1+e} \frac{\Delta e}{\Delta \sigma_{\mathrm{v}}^{\prime}}
$$

where $e$ is the actual voids ratio.

Accordingly the consolidation coefficient and the hydraulic conductivity at $11.4 \mathrm{MPa}$ effective normal stress are $c_{\mathrm{v}} \approx 2.8 \times 10^{-8} \mathrm{~m}^{2} / \mathrm{s}$ and $k_{\mathrm{w}} \approx 10^{-12} \mathrm{~m} / \mathrm{s}$ respectively for the red clay and $c_{\mathrm{v}} \approx 1.3 \times 10^{-8} \mathrm{~m}^{2} / \mathrm{s}$ and $k_{\mathrm{w}} \approx 0.55 \times 10^{-12} \mathrm{~m} / \mathrm{s}$ for the gray clay. The corresponding Muskat or physical permeability is expressed from the hydraulic conductivity as $k=\eta_{\mathrm{w}} k_{\mathrm{w}} / g$ where $\eta_{\mathrm{w}}$ is the kinematic viscosity of water $\left(\eta_{\mathrm{w}}=10^{-6} \mathrm{~m}^{2} / \mathrm{s}\right.$ at $\left.20^{\circ} \mathrm{C}\right)$ and $g$ is the gravity acceleration. We obtain $k \approx 10^{-19} \mathrm{~m}^{2}$ respectively for the red clay and $k \approx 0.55 \times 10^{-19} \mathrm{~m}^{2}$ for the gray clay. In direct permeability tests performed by pumping degassed-deionised water on a sample of the red clay material Song et al. (2004) have obtained ranges of 0.9 to $2 \times 10^{-18} \mathrm{~m}^{2}$. This result is consistent with those published in the literature. For example for the Nojima fault, Lockner et al. (2000) obtain a permeability of about $10^{-19} \mathrm{~m}^{2}$ in the center of the shear zone; the same order of magnitude is obtained by Wibberley and Shimamoto (2003) for the Median Tectonic Line Fault, Japan.

The permeability of geomaterials is classically related to the porosity and to the specific area squared value of some characteristic pore diameter. A frequently used relationship known as the Carman-Kozeny permeability model reads:

$$
k=k_{\mathrm{H}} \frac{n^{3}}{(1-n)^{2}}, \quad k_{\mathrm{H}}=\frac{1}{c_{1}} D_{\mathrm{H}}^{2}
$$

where $D_{\mathrm{H}}$ is the harmonic mean of the grain sizes that makes-up the sample and $c_{1}=18 \pi^{2} \approx 178$ is the so-called Carman-Kozeny constant.

As it can be seen from Fig. 10, the data from permeability measurements suggest that the dependency of the permeability on the porosity holds for powers

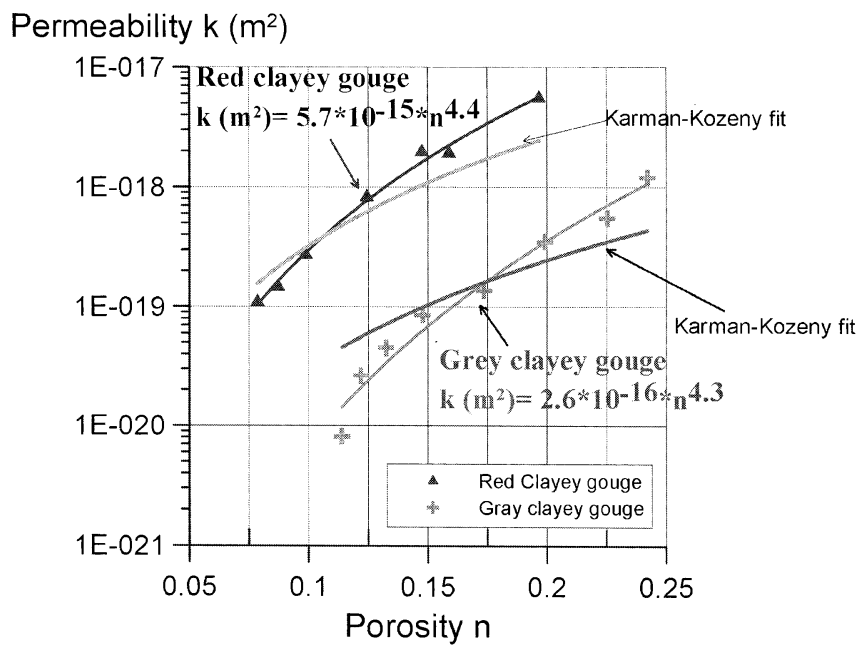

Fig. 10. Permeability-porosity evolution

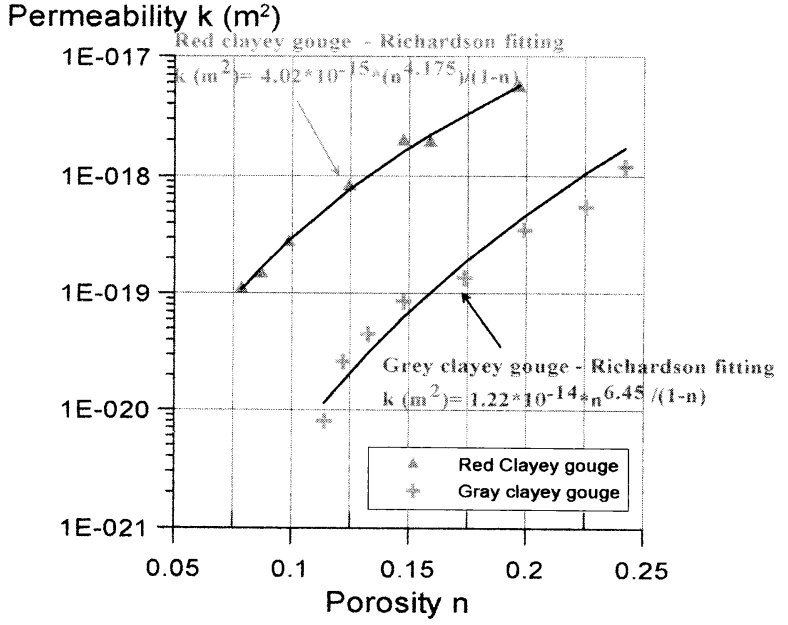

Fig. 11. Richardson law for gouge material

higher than 3. This in turn means that, most probably, during flow the fines are fluidized and that the permeability follows rather Richardson's law (Vardoulakis, 2004)

$$
k=\frac{1}{18} \frac{n^{\mathrm{r}}}{1-n} D_{\mathrm{H}}^{2}
$$

Typically the exponent $r$ in Richardson's law in Eq. (6), is larger than 3. Accordingly, the permeability data have been fitted with Richardson's law (Fig. 11). The corresponding set of constants are given in Table 3

The permeability of the clayey gouge is thus controlled by the finest particles. Here we obtain a characteristic particle size of few tenths of microns which is compatible with the mineral composition of the soil (Tables 2(a) and (b)). The smaller value obtained for the red clayey part is also consistent with the electron scanning microscopy (Fig. 7). 
Table 3. Parameters for the Richardson's permeability, law

\begin{tabular}{c|c|c}
\hline & Red clayey gouge & Gray clayey gouge \\
\hline$D_{\mathrm{H}}$ (microns) & 0.26 & 0.47 \\
\hline$r$ & 4.175 & 6.45 \\
\hline
\end{tabular}

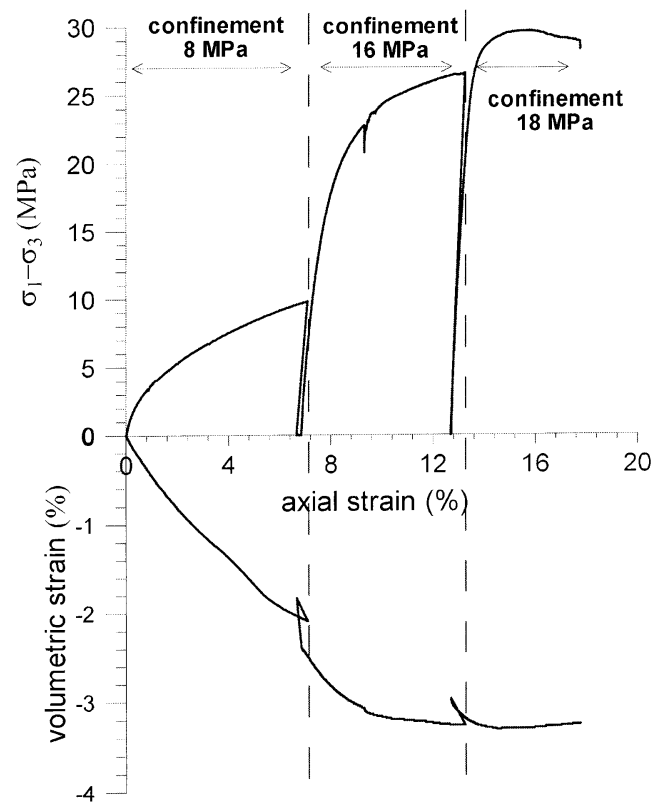

Fig. 12. Drained triaxial tests at room temperature $\left(22^{\circ} \mathrm{C}\right)$

\section{Strength Parameters from Drained Triaxial Compression Tests}

Triaxial compression tests have been performed at room temperature $\left(22^{\circ} \mathrm{C}\right)$ and at $70^{\circ} \mathrm{C}$. The corresponding stress-strain curves are shown respectively on Figs. 12 and 13. At room temperature, for the test at $8 \mathrm{MPa}$ of confining pressure, the loading phase was interrupted at an axial strain of $7.2 \%$ corresponding to a deviatoric stress of $9.9 \mathrm{MPa}$. This deviatoric stress is actually less than the stress at which failure occurs. Thus the same sample could be used for a different higher pressure. For the tests at $16 \mathrm{MPa}$ and $18 \mathrm{MPa}$, the material was compacting and reached the critical state for a maximum friction angle of $27.9^{\circ}$. The dilatant behavior which occurs at the end of the test at $18 \mathrm{MPa}$ of confinement is attributed to the occurrence of shear-banding in the sample.

The frictional resistance at critical state of the material increases slightly with temperature and strain rate. The triaxial experiment run at $70^{\circ} \mathrm{C}$ at the same strain rate as the ones at room temperature $\left(10^{-6} \mathrm{~s}^{-1}\right)$ yielded a maximum friction angle of $29^{\circ}$.

As shown in Fig. 13 changes in the strain rate during the test show also some rate sensitivity for the frictional resistance. A sudden change of the imposed axial strain rate from a value $\dot{\varepsilon}_{\mathrm{a}}^{-}$to a value $\dot{\varepsilon}_{\mathrm{a}}^{+}$induces a jump for the mobilized friction coefficient $\Delta f=f^{+}-f^{-}$. For axisymmetric compression, the mobilized friction coefficient is

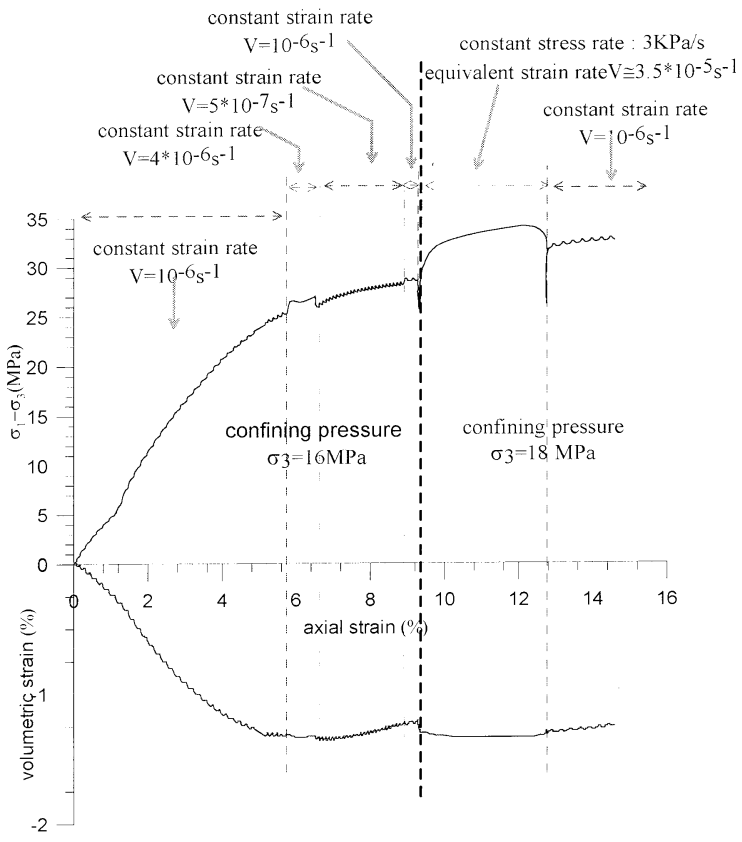

Fig. 13. Drained triaxial tests at $70^{\circ} \mathrm{C}$

expressed in terms of the mobilized friction angle $\phi_{\mathrm{m}}$ as

$$
f=2 \sqrt{3} \sin \phi_{\mathrm{m}} /\left(3-\sin \phi_{\mathrm{m}}\right)
$$

The frictional rate-sensitivity of the red clayey gouge is modeled with a simple strain-rate hardening function as follows:

$$
f=f_{0}\left(\frac{\dot{\varepsilon}}{\dot{\varepsilon}_{0}}\right)^{\mathrm{S}_{\mathrm{r}}}
$$

The exponent $S_{\mathrm{f}}$ of the above power law is evaluated on the experimental data (Fig. 13) and is found:

$$
S_{\mathrm{f}}=\frac{\Delta f /\left(\left(f^{+}+f^{-}\right) / 2\right)}{\ln \left(\frac{\dot{\varepsilon}_{\mathrm{a}}^{+}}{\dot{\varepsilon}_{\mathrm{a}}^{-}}\right)} \approx 0.01
$$

\section{Drained Thermal Loading of the Clayey Gouge}

In order to study the effect of temperature on the volumetric behavior of the material, two tests of drained heating have been performed in isotropic stress conditions. For each test, the sample is first loaded isotropically to its final stress in drained conditions and at constant room temperature. Then by keeping the isotropic stress constant, the sample was heated in drained conditions at a rate of $0.02^{\circ} \mathrm{C} / \mathrm{min}$. The experimental results are shown in Fig. 14. The two tests show a good reproducibility and also show that the final state of isotropic stress is not influencing the response.

The important result from these experiments is that the clay-rich material is contracting, when heated. This phenomenon represents a thermo-plastic or structural collapse. The corresponding elasto-plastic contraction coefficient is negative $\alpha_{\mathrm{c}}^{\mathrm{ep}}=-2.4 \times 10^{-4} /{ }^{\circ} \mathrm{C}$. During the cooling phase thermo-elastic contraction is occurring with a rate of $\alpha_{c}^{e}=1.4 \times 10^{-4} /{ }^{\circ} \mathrm{C}$. Thus the resulting 
isobaric thermo-plastic contraction coefficient is $\alpha_{\mathrm{c}}^{\mathrm{p}}=\alpha_{\mathrm{c}}^{\mathrm{ep}}$ $-\alpha_{c}^{e}=-3.8 \times 10^{-4} /{ }^{\circ} \mathrm{C}$. For the constitutive aspects of thermoplastic collapse we refer here to the paper of Hueckel and Pellegrini (1991). Following Vardoulakis (2002a) the coefficient of thermal pressurization $\lambda$ can be estimated from the above results

$$
\lambda=\left(\frac{\partial p^{\prime}}{\partial \theta}\right)_{\varepsilon=\text { const. }}=-\frac{(\partial \varepsilon / \partial \theta)_{\mathrm{p}^{\prime}}}{\left(\partial \varepsilon / \partial p^{\prime}\right)_{\theta}}=-\frac{\alpha_{\mathrm{c}}^{\mathrm{p}}}{c}
$$

where $\theta$ is the temperature, $p^{\prime}$ the effective mean stress, $\varepsilon$ the volumetric strain, and the compressibility coefficient is given by Eq. (3). The thermal pressurization coefficient is estimated to $0.1 \mathrm{MPa} /{ }^{\circ} \mathrm{C}$.

\section{Remark}

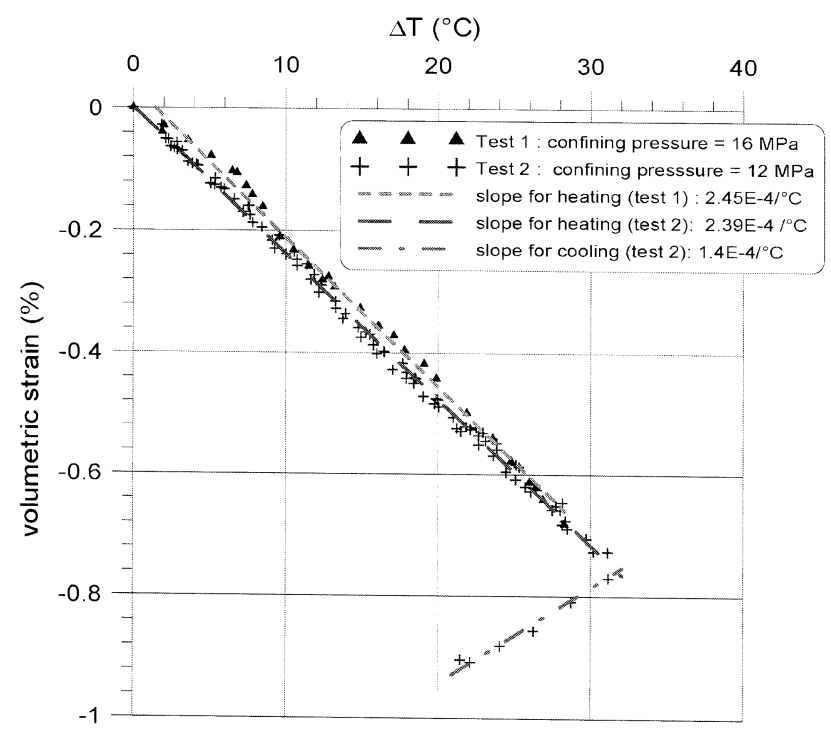

Fig. 14. Drained heating tests under isotropic state of stress
The measurement can be realized directly in a isochoric undrained heating test, where the effective stress is monitored by increasing the temperature and keeping the volume constant. This is however a difficult test that would need an equipment that allows for compensated pore-pressure measurements.

\section{SHEAR BAND ANALYSIS}

In this section the mechanism of shear band formation inside the clayey core is analyzed. The analysis is restricted to a two-dimension configuration. As mentioned above, a clear shear plane is formed at the interface between the gray clay and the red one (Fig. 15). The striation indicates a slip at the centimetric scale (Fig. 15(b)). This plane is oriented with an inclination of $22^{\circ}$ with respect to the horizontal axis. The angle between this slip plane and the fault plane is thus $38^{\circ}$.

Extensive presentation of shear band analysis in geomaterials can be found in Vardoulakis and Sulem (1995). As the reference coordinates system we consider in the following the principal axes of the stress tensor $\left(X_{1}\right.$, $X_{2}$ ). Strain localization in the form of a shear band corresponds to weak discontinuities for the incremental displacement and occurs first when the acoustic tensor $\Gamma$ becomes singular (Hill, 1962):

$$
\operatorname{det}\left(\Gamma_{\mathrm{ij}}\right)=0, \quad \text { with } \quad \Gamma_{\mathrm{ij}}=L_{\mathrm{ijkl}} n_{\mathrm{k}} n_{1}
$$

where $L$ is the incremental constitutive tensor of the material and $n_{\mathrm{i}}$ are the cosines of the normal to the shear band. The Aigion fault gouge is a clay-rock mixture. The axisymmetric compression tests have shown the frictional character of the material. Thus the 2D-constitutive equations of Mohr-Coulomb flow elastoplasticity theory are used here. In the coordinate system of principal axes of initial stress, the incremental equations are:

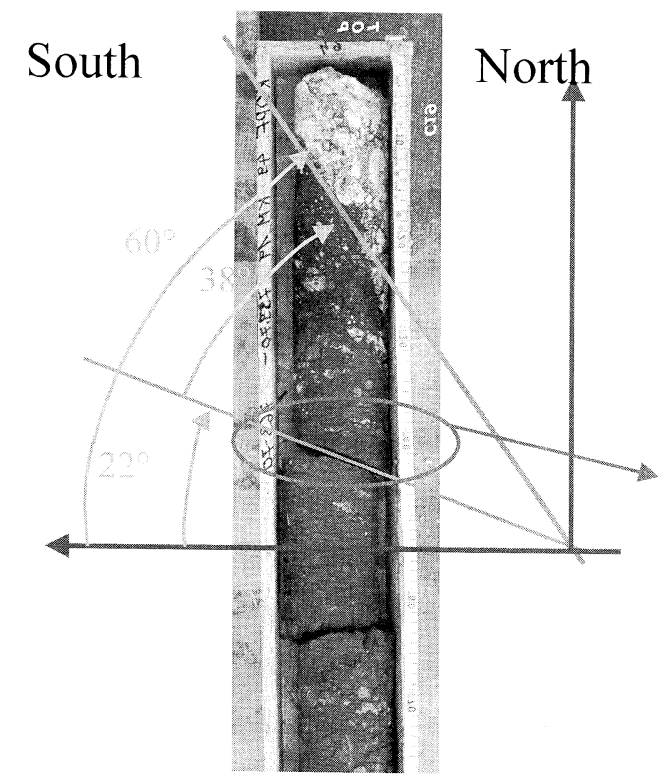

(a)

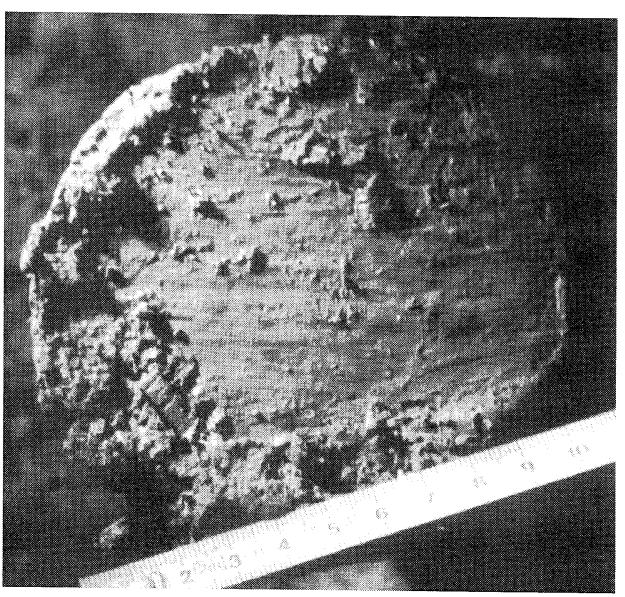

(b)

Fig. 15. (a) The clayey core retrieved from Aigion fault and (b) Striation of the slip plane 


$$
\begin{aligned}
\Delta \sigma_{11} & =L_{11} \Delta \varepsilon_{11}+L_{12} \Delta \varepsilon_{22} \\
\Delta \sigma_{22} & =L_{21} \Delta \varepsilon_{11}+L_{22} \Delta \varepsilon_{22} \\
\Delta \sigma_{12} & =2 G \Delta \varepsilon_{12}
\end{aligned}
$$

where for the considered 2D-continuum model

$$
\begin{aligned}
& L_{11}=G\left(1+\kappa-\frac{1}{H}(1+\kappa f)(1+\kappa d)\right) \\
& L_{12}=G\left(-1+\kappa-\frac{1}{H}(1+\kappa f)(-1+\kappa d)\right) \\
& L_{21}=G\left(-1+\kappa-\frac{1}{H}(-1+\kappa f)(1+\kappa d)\right) \\
& L_{22}=G\left(1+\kappa-\frac{1}{H}(-1+\kappa f)(-1+\kappa d)\right)
\end{aligned}
$$

In Eq. (13), $G$ is the elastic shear modulus, $\kappa=1 /(1-2 v)$ ( $v$ is the Poisson's ratio), $H=1+h$ is the plastic modulus ( $h$ is the hardening modulus), $f$ is the friction coefficient and $d$ is the dilatancy coefficient. These parameters are deduced from the calibration of the elastoplastic parameters on the triaxial test data of the red clayey gouge. The elastic parameters at a reference state of stress which corresponds to $760 \mathrm{~m}$ depth are $G \approx 750 \mathrm{MPa}$ and $v=0.2$. In triaxial tests, it is obtained that shear banding is occurring at the limit state of maximum friction coefficient (i.e. $f=\sin \phi, \phi=28^{\circ}, h=0$ ) and at critical state (i.e. $d=0$ ). It is assumed that for the $2 \mathrm{D}$ problem, the same conditions are met.

The solution for the shear band condition (11) corresponds to a shear band inclination of $51.8^{\circ}$ with respect to the minor (in absolute value) principal stress axis. This solution is very close to the so-called Roscoe solution $45^{\circ}+\phi / 4=52^{\circ}$. More generally in plane strain deformation the orientation of the shear band is well approximated by the simple formula $\theta_{\mathrm{B}}=45^{\circ}+\phi / 4+\psi / 4$ where $\psi$ is the dilatancy angle (equal to zero at shear banding here) (Arthur et al., 1977; Vardoulakis, 1980; Vardoulakis and Sulem, 1995).

From this result and from the observation that the slip surface is oriented at an angle of about $22^{\circ}$ with respect to the horizontal axis, we deduce that the principal stress axes are rotated with an angle of $29.8^{\circ}$ with respect to the horizontal and vertical axes. They correspond approximately to the directions that are normal and parallel to the major fault (oriented at $60^{\circ}$ ) (Fig. 16). This result should be corroborated with in-situ direct stress measurements. It is compatible with the general observation that in weak fault zones the fault actually support very little shear stress like for example the San Andreas Fault (California) (Lachenbruch and Sass, 1992).

\section{APPLICATION TO RAPID SHEARING}

We consider a rapidly deforming and long shear band of thickness $d_{\mathrm{B}}$ consisting of water-saturated material soil. Inside such a shear-band the pore-pressure $p(t, z)$, the temperature $\theta(t, z)$ and the velocity $v(t, z)$ are assumed to be functions only of the time $t$ and of the

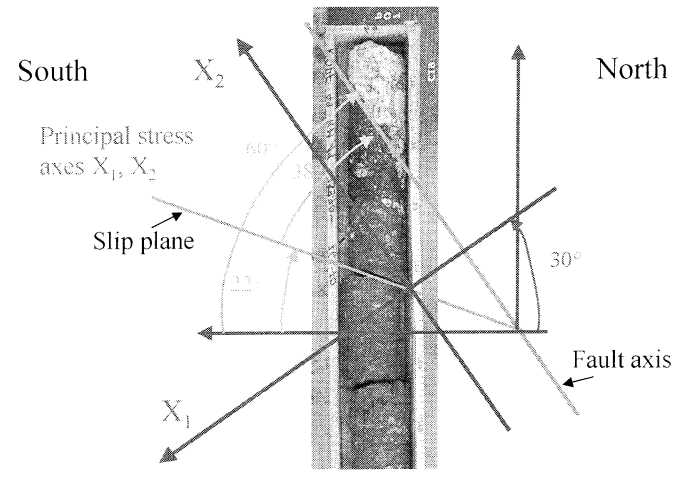

Fig. 16. Principal stress axes as deduced from shear band analysis: $X_{1}$ is the minor (in absolute value) principal axis

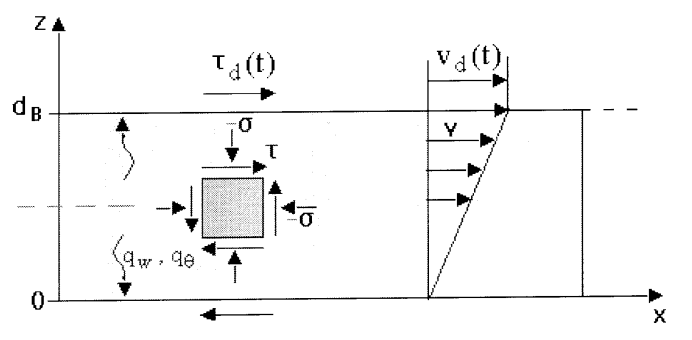

Fig. 17. The deforming shear-band with heat and fluid fluxes

position $z$ in normal to the band direction (Fig. 17).

The equations that govern the problem of dynamic, thermo-poro-plastic shearing can be found in Vardoulakis (2000, 2002a). They are derived from the corresponding balance laws for mass, momentum and energy for a two-phase saturated porous medium.

A significant simplification of the mathematical model, arises if one neglects the diffusion of heat in the surroundings of the rapidly deforming shear-band. This case corresponds to the so-called adiabatic limit. On top of that the model may be simplified further, if one neglects pore-pressure diffusion as well, which corresponds to the 'undrained' limit. The undrained adiabatic limit is applicable as soon as the slip event is rapid.

We introduce the following set of dimensionless independent and dependent variables

$$
\begin{aligned}
z^{*} & =\frac{z}{d_{\mathrm{ref}}}, \quad t^{*}=\frac{t}{t_{\mathrm{ref}}} \geq 0 \\
v^{*} & =\frac{v}{v_{\mathrm{ref}}} \\
p^{*} & =\frac{p}{p_{\mathrm{ref}}} \\
\theta^{*} & =\frac{\theta}{\theta_{\mathrm{ref}}}
\end{aligned}
$$

where as reference quantities we select the following: Reference length: shear-band thickness, $d_{\text {ref }}=2 d_{\mathrm{B}}$. Reference velocity: the slip velocity, $v_{\text {ref }}=v_{\text {slip }}$.

Reference pressure: the geostatic pressure, $p=\sigma_{\mathrm{v} \text {,total }}$; i.e. initially the pore-pressure is hydrostatic, $p=p_{0}$ and with 
that $p_{0}^{*}=\left(p_{0} / \sigma_{\mathrm{v}, \text { total }}\right)<1$ and finally it becomes geostatic, $p=\sigma_{\mathrm{v}, \text { total }}$ and with that $p_{0}^{*}=1$.

Reference temperature: the ambient temperature. $\theta_{\text {ref }}=$ $\theta_{\mathrm{amb}}$

The reference time is given as, $t_{\text {ref }}=\left(d_{\text {ref }} / v_{\text {ref }}\right)$

In addition we define the following dimensionless numbers

$$
\begin{aligned}
\lambda^{*} & =\frac{\lambda \theta_{\text {ref }}}{p_{\text {ref }}} \\
\eta^{*} & =\frac{p_{\text {ref }}}{\left(\rho_{\mathrm{m} j} j C_{\mathrm{m}}\right) \theta_{\text {ref }}} \tan \phi
\end{aligned}
$$

where $j$ is the mechanical equivalent of heat $(j=4.2 \mathrm{~J} /$ cal), the parameters $\rho_{\mathrm{m}}$ and $C_{\mathrm{m}}$ are the density and the specific heat of the saturated soil and $\phi$ is the friction angle of the gouge.

We obtain the following set of governing evolution equations (in terms of dimensionless variables and by avoiding the superimposed asterix),

$$
\begin{aligned}
& \frac{d p}{d t}=\lambda \frac{d \theta}{d t} \\
& \frac{d \theta}{d t}=\eta(1-p) v
\end{aligned}
$$

From the last two equations we may eliminate the temperature and we obtain the following pore-pressure evolution equation

$$
\frac{d p}{d t}=\beta(1-p) v, \quad \beta=\lambda \eta=\frac{\lambda}{(\rho j C)_{\mathrm{m}}} \tan \phi
$$

Thus

$$
\begin{aligned}
& -\ln \left(\frac{(1-p)}{\left(1-p_{0}\right)}\right)=\beta \int_{0}^{t} v d t \\
& p=1-\left(1-p_{0}\right) e^{-\beta u}
\end{aligned}
$$

This means that in terms of dimensionless variables the pore-pressure increases towards its geostatic limit that corresponds to full fluidization exponentially with the slip displacement, $u=\int v d t$. The governing physical factor is the coefficient $\beta$, which combines the effects of friction and temperature-pressure coupling and depends also on the specific heat of the mixture.

In the undrained adiabatic limit we impose an ad-hoc solution for the velocity field;

$$
v=v_{\text {ref }} \frac{z}{d_{\mathrm{B}}}
$$

The solution is built for constant velocity. The solution obtained for constant friction is thus not changed. Only coefficient $\beta$ is modified

$$
\beta=\frac{\lambda}{(\rho j C)_{\mathrm{m}}} \tan \phi
$$

with

$$
\tan \phi \approx \tan \phi_{\text {ref }}\left(\frac{v}{v_{\text {ref }}}\right)^{\mathrm{S}_{\mathrm{f}}}
$$

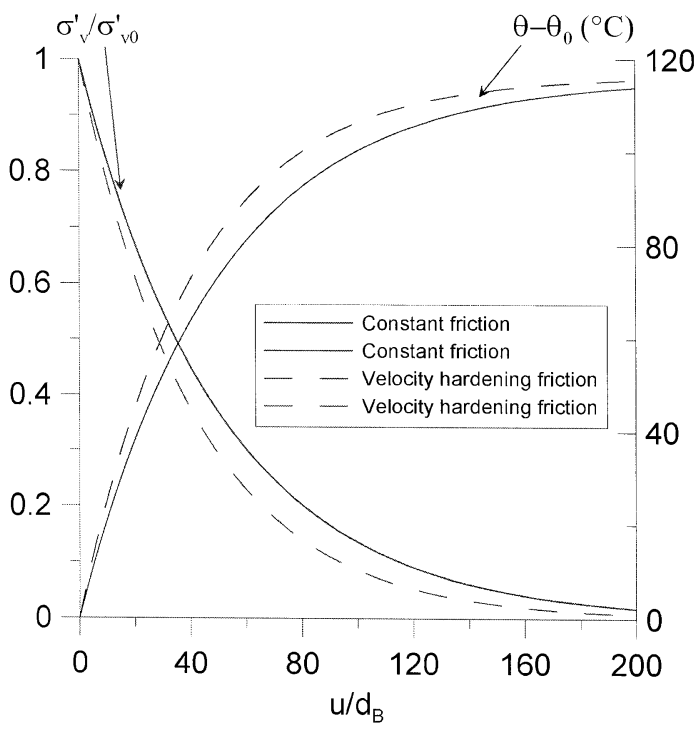

Fig. 18. Shear-heating and fluid pressurization

In the above equation the exponent $S_{\mathrm{f}}$ is given by Eq. (9), and $\tan \phi_{\text {ref }}=0.5 ; S_{\mathrm{f}}=0.01 ; v_{\text {ref }}$ (in the triaxial test) $=$ $10^{-6} / \mathrm{s}$.

If we assume a boundary imposed velocity of $v=1 \mathrm{~m} / \mathrm{s}$ for $d_{\mathrm{B}} \approx 1 \mathrm{~mm}$ it corresponds to a shear strain rate of

$$
\dot{\gamma}=\frac{v}{d_{\mathrm{B}}} \approx 10^{3} \mathrm{sec}^{-1}
$$

We obtain

$$
\begin{gathered}
\tan \phi \approx \tan \phi_{\text {ref }}\left(\frac{v}{v_{\text {ref }}}\right)^{\mathrm{S}_{\mathrm{r}}}=0.5 *\left(\frac{10^{3}}{10^{-6}}\right)^{0.01} \\
=0.5 * 1.23=0.61 \\
\beta=\frac{\lambda}{(\rho j C)_{\mathrm{m}}} \tan \phi=0.246
\end{gathered}
$$

Although it is a strong assumption to extrapolate the strain rate hardening function (Eq. (23)) obtained from laboratory strain rates to seismic strain rates from the figure we may see the corresponding trends; it results into a slight amplification of the effects of pressurization and shear heating.

The results of the evolution of the temperature and of the effective stress are shown on Fig. 18 as a function of the normalized displacement $u / d_{\mathrm{B}}$ for constant friction and for velocity hardening friction. A key parameter is the actual shear-band thickness. It appears that in the clayey core of the fault zone, an 'ultra-localized' zone of highly strained material is formed. The thickness of this zone is of the order of tenths of mm despite a much wider fault zone (Cocco and Rice, 2002). Thus slip at a centimetric scale can actually induce fluidization of the material inside the shear-band.

\section{CONCLUSION}

In rapid fault shearing of clay-rich faults the effects of pore-water heating and consequent pore-pressure rise 
cannot be disregarded. Thermal run-away instabilities are possible to occur as soon as the particular clay shows frictional strain-rate hardening and thermal softening. The experimental characterization program performed on fault zone cores extracted from Aigion fault at a depth of $760 \mathrm{~m}$ has shown that the Aigion fault gouge is a clayrock mixture. Although the clay fraction is relatively small, it has a significant influence on the thermomechanical properties of the material. The clayey core of the fault has a very low fluid permeability and exhibits contractant volumetric behavior when heated. The sensitive parameter for the description of the thermo-poromechanical coupling is the thermal pressurization coefficient of the material. It was found that at a nominal effective stress corresponding to $760 \mathrm{~m}$ deep conditions, this coefficient is about $0.1 \mathrm{MPa} /{ }^{\circ} \mathrm{C}$. An analysis of undrained and adiabatic shearing of a thin layer of this clayey gouge has shown that shear heating and fluid pressurization is a possible mechanism leading to full fluidization of the material inside the shear band. It is shown that an important parameter of the problem is the thickness of the zone where highly localized deformation actually occurs as an individual slip event that can lead to run-away instability phenomenon in the fault zone. We emphasize the fact that the parameters used in the analysis are the ones of a fault gouge at $760 \mathrm{~m}$ depth. The actual nature and rheology of materials at seismogenic depth is a challenging question that can only be answered in the future by ultra-deep drilling.

On the basis of an elastoplastic constitutive model calibrated on triaxial tests on the clayey gouge, it is shown that shear band formation inside the clayey core is possible. The solution for the orientation of the shear band is compared to the orientation of an existing slip surface inside the clayey gouge and this result is used to deduce the orientation of the principal stresses. It is shown that as commonly observed in weak fault zones, the orientation of the principal stresses is locally parallel and perpendicular to the fault axis. This result should be corroborated in a near future with in-situ direct stress measurements with the Corinth Rift Laboratory project.

\section{ACKNOWLEDGEMENTS}

The authors wish to acknowledge the EU projects 'DG-Lab Corinth' (EVR1-CT-2000-40005) and 'Fault, Fractures and Fluids: Golf of Corinth', in the framework of Energy program (ENK6-2000-0056) and 'Degradation and Instabilities in Geomaterials with Applications to Hazard Mitigation' (DIGA) in the framework of the Human Potential Program, Research Training Network (HPRN-CT-20002-00220) and the 'Groupement de Recherche Corinthe' (GDR 2343), INSU-CNRS for supporting this research.

\section{REFERENCES}

1) Arthur, J. R. F., Dunstan, T., Al-Ani, Q. A. J. and Assadi, A. (1977): Plastic deformation and failure in granular media,
Geotechnique, 42, 395-410.

2) Cocco, M. and Rice, J. R. (2002): Pore pressure and poroelasticity effects in Coulomb stress analysis of earthquake interactions, $J$. Geophysical Research, 107(B2), 1-17.

3) Cornet, F., Bernard, P. and Moretti, I. (2004a): The Corinth Rift Laboratory, Comptes Rendus Geosciences, 336, 4-5, 235-242.

4) Cornet, F., Doan, M. L., Moretti, I. and Borm, G. (2004b): Drilling through the active Aigion Fault: the AIG10 well observatory, Comptes Rendus Geosciences, 336, 4-5, 395-406.

5) Daniel, J. M., Moretti, I., Micarelli, L., Essautier Chuyne, S. and Delle Piane, C. (2004): Macroscopic structural analysis of AG10 well (Gulf of Corinth, Greece), Comptes Rendus Geosciences, 336, $4-5,435-444$.

6) Garagash, D. I. and Rudnicki, J. W. (2003): Shear heating of a fluid-saturated slip-weakening dilatant fault zone 1. Limiting regimes, J. Geoph. Res., 108, B2, 2121.

7) Hill, R. (1962): Acceleration waves in solids. J. Mech. Phys. Solids, 10, $1-16$.

8) Hueckel, T. and Pellegrini, R. (1991): Thermoplastic modelling of undrained failure of saturated clay due to heating. Soils and Foundations, 31(3), 1-16.

9) Lachenbruch, A. H. (1980): Frictional heating, fluid pressure and the resistance to fault motion. J. of Geophys. Res., 85, 6097-6112.

10) Lachenbruch, A. H. and Sass, J. H. (1992): Heat flow from Cajon Pass, fault strength, and tectonic implications. J. Geophys. Res., 97 B4, 4995-5015.

11) Lockner, D., Naka, H., Tanaka, H., Ito, H. and Ikeda, R. (2000): Permeability and strength of core samples from the Nojima fault of the 1995 Kobe earthquake, USGS Open File Rpt., 00-129.

12) Marcial, D., Delage, P. and Cui, Y. J. (2002): On the high stress compression of bentonites, Can. Geotech. J., 39, 812-820.

13) Mase, C. W. and Smith, L. (1985): Pore-fluid pressures and frictional heating on a fault surface, Pageoph., 122, 583-607.

14) Micarelli, L., Moretti, I. and Daniel, J. M. (2003): Structural properties of rift-related normal faults: the case study of the Gulf of Corinth, Greece, J. Geodynamics, 36, 275-303.

15) Moretti, I., Sakellariou, D., Likoussis, V. and Micarelli, L. (2003): The Gulf of Corinth: an active graben?, J. Geodynamics, 36, 323-340.

16) Otsuki, K., Monzawa, C. W. and Nagase, T. (2003): Fluidization and melting of fault gouge during seismic slip: Identification in the Nojima fault zone and implications for focal earthquake mechanisms. J. Geophysical Research, 108, no. b4, 2192.

17) Rettenmaier, D., Giurgea, V., Hötzl, H. and Förster, A. (2004): The AIG10 drilling project (Aigion, Greece): interpretation of the litho-log in the context of regional geology and tectonics, Comptes Rendus Geosciences, 336, 4-5, 415-424.

18) Song, I., Elphick, S. C., Odling, N., Main, I. G. and Ngwenya, B. T. (2004): Hydromechanical behaviour of fine-grained calcilutite and fault gouge from the Aigion Fault Zone, Greece, Comptes Rendus Geosciences, 336, 4-5, 445-454

19) Sulem, J., Vardoulakis, I., Ouffroukh, H., Boulon, M. and Hans, J. (2004): Experimental characterization of the thermo-poromechanical properties of the Aegion fault gouge, Comptes Rendus Geosciences, 336, 4-5, 455-466.

20) Sultan, N., Delage, P. and Cui, Y. J. (2000): Comportement thermomécanique de l'argile de Boom. Comptes Rendus Académie des Sciences, Paris, 328, Série Iib, 457-463.

21) Tselentis, G. A. and Makropoulos, K. (1986): Rates of crustal deformation in the Gulf of Corinth (central Greece) as determined from seismicity. Tectonophysics, 24, 55-61.

22) Vardoulakis, I. (1980): Shear band inclination and shear modulus of sand in biaxial tests. Int. J. Num. Anal. Meth. Geomech., 4, 3-119.

23) Vardoulakis, I. (2000): Catastrophic landslides due to frictional heating of the failure plane. Mech. Coh. Frict. Mat., 5, 443-467.

24) Vardoulakis, I. (2002a): Dynamic thermo-poro-mechanical stability analysis of simple shear on frictional materials, Modelling and Mechanics of Granular and Porous Materials (eds. by Capriz, G., Ghionna, V. N. and Giovine, P.), Birkhäuser Verlag, Boston, Ch. $5,2002 \mathrm{a}, 129-150$ 
25) Vardoulakis, I. (2002b): Steady shear and thermal run-away in clayey gouges. Int. J. Solids Structures, 39, 3831-3844.

26) Vardoulakis, I. (2004): Fluidisation in artesian flow conditions: Hydromechanically stable granular media, Géotechnique, 54(2), 117-130.

27) Vardoulakis, I. and Sulem, J. (1995): Bifurcation Analysis in
Geomechanics, Chapman \& Hall.

28) Wibberley, C. and Shimamoto, T. (2003): Internal structure and permeability of major strike-slip fault zones: the Median Tectonic Line in Mie Prefecture, Southwest Japan, J. Structural Geology, 25, 59-78. 